PNL-SA-24899

DEPTH ENHANCEMENT TECHNIQUES FOR THE IN SITU VITRIFICATION PROCESS
P. S. Lowery '
J. S. Tixier
J. Luey
C. L. Timmerman ${ }^{(a)}$
D. K. Seiler

November 1994

Presented at the

Thirty-Third Hanford Symposium on Health and the

Environment Conference

November 7-11, 1994

Richland, Washington

Prepared for

the U.S. Department of Energy

under Contract DE-AC06-76RLO 1830

Pacific Northwest Laboratory

Richland, Washington 99352

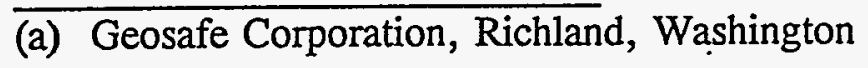

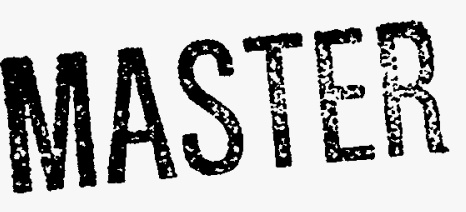




\section{DISCLAIMER}

Portions of this document may be illegible in electronic image products. Images are produced from the best available original document. 


\title{
DEPTH ENHANCEMENT TECHNIQUES FOR IN SITU VITRIFICATION
} PROCESS

\author{
P. S. Lowery ${ }^{1}$, J. Luey1, D. K. Seiler'1, J. S. Tixier ${ }^{1}$, and C. L. Timmerman ${ }^{2}$ \\ 1Pacific Northwest Laboratory, Richland, Washington \\ 2Geosafe Corporation, Richland, Washington
}

Key Words: In Situ Vitrification, Joule heat, molten soillwaste matrix, depth enhancement,
thermo-fluid modeling, in-situ, in-situ thermal

Running Head: In-Situ Vitrification Depth Enhancement

\section{ABSTRACT}

Results obtained from application of two novel approaches for extending the ultimate treatment depth attainable with in-situ vitrification (ISV) are presented. In the first, the electrode design is modified to concentrate the Joule heat energy delivered to the soil/waste matrix in the lower region of the target melt zone. This electrode design has been dubbed the "hot-tip" electrode. Results obtained from both computational and experimental investigations of this design concept indicate that some benefit toward ISV depth enhancement was realized with these hot-tip electrodes.

A second, alternative approach to extending process depth with ISV involves initiating the melt at depth and propagating it in either vertical direction (e.g., downward, upward, or both) to treat the target waste zone. A series of engineering-scale experiments have been conducted to assess the benefits of this approach. The results from these tests indicate that ISV may be effectively initiated and sustained using this subsurface start-up technique. A survey of these experiments and the associated results are presented herein, together with brief discussion of some considerations regarding setup and implementation of this subsurface start-up technique. 


\section{INTRODUCTION}

In-situ vitrification (ISV) is a process by which electrical energy is supplied to a soil/waste matrix. The resulting Joule heat raises the temperature of the soil/waste matrix, producing a pool of molten soil. The ISV process was invented in the early 1980 s by researchers at Pacific Northwest

Laboratory (PNL) for the U.S. Department of Energy (DOE) and was patented in 1983 (Brouns et al. 1983). It is has been licensed by DOE to Battelle Memorial Institute which has granted exclusive sublicense to the Geosafe Corporation for commercial applications.

Since its inception, there have been many successful applications of the technology to both staged and actual waste sites. However, there has been some difficulty in extending the attainable treatment melt depth to levels greater than $5 \mathrm{~m}$. This difficulty may be the result of characteristics unique to the sites processed or it may be an inherent limitation in the design and application of the currently used ISV systems.

Numerous system modifications have been postulated to facilitate reaching the target melt depth at any given site. In this presentation, two different approaches to address the depth limitation issue are presented: 1) a modification to the standard electrode design and 2) a modification to the standard ISV operating sequence. The design concept for the modified standard electrode holds great promise for achieving target depths while simultaneously requiring minimal alteration to the ISV system and its operational procedures. In this concept, only the lower portion of the electrode supplies current to the melt pool. For the modification to the standard ISV operating sequence, initiation of the ISV process in the subsurface (rather than at the surface) is being evaluated. This concept holds great promise for achieving target depths by initiating the ISV process at depth and allowing the molten pool to grow downward, outward, upward, or a combination of all three directions, depending on the necessary treatment volume. PNL's recent experimental and 
modeling experience using these two concepts will be presented.

\section{ENGINEERING-SCALE HOT-TIP ELECTRODE RESULTS}

Numerical simulations of the ISV process have been performed using the TEMPEST code (Trent and Eyler. 1993.). In these simulations, we compute the thermo-fluid response of the ISV system by solving a discretized form of coupled partial differential equations that describe the conservation of mass, momentum, energy, and electric charge. Temperature-dependent thermal, electrical, and transport properties included in the model were obtained from Buelt et al. (1987). Multi-phase, multi-electrode systems are also explicitly modeled in these simulations.

A typical two-phase, four-electrode engineering-scale ISV system was modeled in these simulations. In this configuration, a Scott-Tee power supply was used to provide two-phase power (with $90^{\circ}$ phase separation) to the melt through four 5 -cm-dia graphite electrodes. These electrodes were placed in the soil at the vertices of a square pattern. Each diagonally opposed pair of electrodes receives power from one phase of the Scott-Tee system. Center-to-center spacing for these electrode pairs was $0.43 \mathrm{~m}$. A nominal total power level of $25 \mathrm{~kW}$ (split equally between phases) was modeled. For the base-case electrode configuration, the entire length of the electrode supplied current to the melt. In the hot-tip electrode configuration, however, the upper portion of the electrode was electrically insulated from the melt. Current supply to the melt was therefore restricted to the lower portion of the electrode.

Figure 1 illustrates the isotherms on a vertical plane cut through the melt when the system is at a melt depth of $1 \mathrm{~m}$. This plane also passes through two adjoining electrodes of the engineeringscale setup (NOT the diagonally opposed electrode pair, however). These isotherms indicate the temperature distribution in the melt in this state. Both the base case (Figure 1A) and hot-tip (Figure 
1B) results are presented in this figure. A hot-tip length of $27 \mathrm{~cm}$ was assumed in these "case B" results. Therefore, the hot-tip length represents approximately $27 \%$ of the melt depth below grade : at this point in the process. As indicated in this figure, the hot-tip electrodes effectively lower the hot zone of the melt to the lower region of the melt's depth. This has the beneficial effect of increasing the heat flux out the bottom of the melt relative to the base-case configuration results. Since the melt growth rate is proportional to the local heat flux, this increase in heat flux out the bottom of the melt effectively increases the melt's downward growth rate. As a consequence, downward progression of the melt is enhanced by the presence of these hot-tip electrodes. The net effect of these hot-tip electrodes is to reduce the time required to achieve a specified melt depth. For example, in this engineering-scale configuration with a hot-tip length of $27 \mathrm{~cm}$, the simulations indicate that a $1-\mathrm{m}$ melt depth will be attained in $24 \mathrm{hr}$ (or approximately $30 \%$ less time than with standard electrodes). The hot-tip electrodes should also serve to increase the ultimate depth attainable with ISV, since the energy is more efficiently distributed throughout the melt zone.

A series of two engineering-scale experiments were performed in collaboration with the Geosafe Corporation in November, 1993 to assess the efficacy of the hot-tip electrode concept. The first of these tests used the standard electrode and engineering-scale system described in the modeling discussion above. This test served as a baseline against which to compare the results obtained in follow-on hot-tip electrode tests. A steady-state power level of approximately $26 \mathrm{~kW}$ was maintained throughout much of this test. Each test was performed in sandy soil (similar to that found on the Hanford site in Washington state). Every effort was made to reproduce the conditions from one test to the other except for the electrode designs, which differed between tests. For the second test, a castable, refractory, insulative coating was applied to the electrode segments to produce a hot-tip electrode with a hot-tip length of $30 \mathrm{~cm}$. For the base-case test, the electrodes were set in the soil to an initial depth of $7.5 \mathrm{~cm}$. In the hot-tip test however, the electrodes were inserted to an initial depth of $18 \mathrm{~cm}$. This was done to ensure that the top of the uppermost, coated 
electrode segment was below the level of the top plate on the off-gas hood. The insulative coating was sufficiently thick so that it could not extend through the electrode seals of the existing off-gas ! hood. As will be seen in the electrode depth results, this difference had virtually no effect on the overall electrode depth penetration rate after the initial start-up transient. In both tests, power was ramped up to the $26 \mathrm{~kW}$ steady-state level in approximately $2.5 \mathrm{hr}$. Both tests were heavily instrumented with over 200 type $K$ thermocouples to provide a detailed representation of the melt's growth. A plan view illustrating thermocouple placement employed in each test is presented in Figure 2.

Figure 3 illustrates the electrode depth transients realized in both the base case and hot-tip case tests. Note that the hot-tip electrode case reached the targeted 1-m melt depth in approximately 25 hr. The base-case test reached the targeted 1-m depth in $29 \mathrm{hr}$. Thus, this hot-tip configuration resulted in a $17 \%$ reduction in the time required to reach the target depth. Figure 4 illustrates the location and shape of the $500^{\circ} \mathrm{C}, 300^{\circ} \mathrm{C}$, and $200^{\circ} \mathrm{C}$ isotherms in both the base-case and hot-tip case tests. These isotherms suggest the outline of the melt profile along the $0^{\circ}$ axis (reference coordinate system presented in Figure 2) at $25 \mathrm{hr}$ after the start of each test. As these contours.indicate, the hot-tip electrodes provide a deeper, narrower melt shape than the base case. This shape is another manifestation of the concentration of Joule heat in the lower regions of the melt that is realized with the hot-tip electrodes.

The base-case test consumed $749.1 \mathrm{kWh}$ to produce a $727-\mathrm{kg}$ block. This corresponds to a specific energy consumption of $1.03 \mathrm{kWh} / \mathrm{kg}$. The hot-tip test consumed $664.8 \mathrm{kWh}$ and produced a block of $636 \mathrm{~kg}$, corresponding to a specific energy consumption of $1.045 \mathrm{kWh} / \mathrm{kg}$. These values are consistent with the nominal $1 \mathrm{kWh} / \mathrm{kg}$ specific energy consumption typical of engineering-scale melts in sandy soils like those found at the Hanford site in Washington state. The slightly higher specific energy consumption of the hot-tip case may be due to differences in 
heat loss out the top surface of the melt.

Future tests will investigate the effect of hot-tip length and electrode design on the melt rate.

Pending the results of these tests, additional study is are planned to assess the impact of scale (viz., Engineering vs. Pilot \& Large Scale systems) on the performance of these electrodes.

\section{INITIATION OF THE ISV PROCESS AT DEPTH}

The standard ISV process is initiated at the surface and propagated downward and outward until a target volume of a soil/waste matrix has been treated. To initiate the process, starter material (a mixture of graphite and glass frit) is placed in linear trenches between an array of four electrodes. This starter path connects diagonally opposed electrodes as well as adjacent electrodes. A starter path is necessary because soil is not sufficiently electrically conductive until it becomes molten. Once the soil/waste matrix becomes molten from the heated starter path, ions in the molten soil (such as sodium and potassium) become conductors for the supplied electrical power.

For the initiation of the ISV process at a target depth, the key step is the creation of a conductive region between the electrode array that is sufficient for starting the vitrification process. Multiple techniques evaluated included such technologies as directional drilling, direct injection, pneumatic fracturing, and hydraulic fracturing. Each of these techniques could be used to place starter material at a target depth. However, during evaluation of these different techniques, it became apparent that the two fundamental questions exist for the application of ISV in the subsurface are: 1) What starter path geometries are suitable for initiating the ISV process? and 2) Can the ISV process be initiated in the subsurface and propagated in a downward direction?

To answer the first question, a series of engineering-scale ISV tests were performed with different 
starter-path geometries. Three-electrode and four-electrode configurations were investigated for both a planar and a tubular starter-path arrangement. Tests performed with a planar starter-path geometry utilized a 1-cm thick layer of ISV starter material that encompassed the entire electrode array. The starter-tube arrangement for the four- electrode test connected only diagonally-opposed electrode pairs. In the three-electrode test with tubular starter paths, however, all electrode pairs were connected with the starter tubes. The results of these tests indicate that all of the different starter-path geometries were suitable for initiating the ISV process. Based on the results of these engineering-scale tests, it was not possible to eliminate any potential methods for creating a conductive region between an electrode array based on the resulting geometry formed.

To answer the second question related to initiating the ISV process at a target depth, an engineeringscale test was performed in which the process was started at depth. This test was the second engineering-scale test performed in the soil subsurface (Tixier, Stottlemyre, and Murphy 1991) $\therefore$ and the first to explore the propagation of the ISV melt. Previous work was focused on the establishment of a vitrified barrier in the soil subsurface. Figures 5 and 6 illustrate the engineeringscale test layout plan and elevation views, respectively. (For a complete description of PNL's engineering-scale unit and the three-electrode power supply system, see Luey et al., 1992). A planar starter path $85 \mathrm{~cm}$ in diameter and approximately $1 \mathrm{~cm}$ thick was used to initiate the ISV process. The starter path was buried at a depth of $60 \mathrm{~cm}$ below grade. Stove pipes (15-cm-dia) were used to simulate well casings for the 5 -cm-dia electrodes as well as a central vent pipe. A total of 19 type $K$ thermocouples were used to monitor temperatures above, below, and to the side of the vitrification zone. The thermocouple array above the starter path was suspended from above the soil surface to ensure a constant position. The lateral thermocouple arrays and arrays located below the starter path were staged as the engineering-scale unit was backfilled with soil.

The engineering-scale test was conducted in the first half of 1994. Power was terminated after 
$22.8 \mathrm{hr}$ of operation when the shutdown criterion was reached (i.e., the type $\mathrm{K}$ thermocouple at a depth of $120 \mathrm{~cm}$ reached a temperature of $1200^{\circ} \mathrm{C}$ ). Figure 7 illustrates the power time-history for the engineering-scale test. During the start-up phase of the test, the power supplied to the soil was increased at a rate of $1 \mathrm{~kW}$ every $6 \mathrm{~min}$ until the target power level of $30 \mathrm{~kW}$ was achieved. Figure 7 also illustrates the total energy consumption for this test. Approximately $645 \mathrm{kWh}$ were used in this test to produce a final block weighing $840 \mathrm{~kg}$. This results in a specific energy consumption of $0.77 \mathrm{kWh} / \mathrm{kg}$.

Figure 8 illustrates the average melt rate downward, as determined from the insertion depths of the electrodes. Between hours 3 and 5 , the melt rate was nearly $7.5 \mathrm{~cm} / \mathrm{hr}$, which is higher than the normal $2.5 \mathrm{~cm} / \mathrm{hr}$ rate seen for the remainder of the engineering-scale test. From experience gained with the engineering-scale tests investigating starter-path geometries, this period of higher than normal melt rate can be attributed to the fact that the molten soil pool begins to form around the electrodes rather than uniformly throughout the starter-path region. This is further supported by the fact that the rate at which the temperature gradient propagated downward along the centerline thermocouple array lagged the insertion rate of the electrodes.

Figure 9 shows the centerline thermocouple temperatures below the starter path. In this figure, the thermocouple type and location are identified with a 12-character tag. The first three letters of this tag (e.g., TCK) indicate thermocouple type (in this case, type $\mathrm{K}$ ). The following nine numbers indicate the thermocouple's depth, radial, and azimuthal location (i.e., zzzrrr $\theta \theta \theta$ in units of $\mathrm{cm}$, $\mathrm{cm}$, and degrees, respectively) relative to the soil surface $(z=0 \mathrm{~cm})$ and horizontal coordinate system indicated in Figure 5. At $7 \mathrm{hr}$ after startup, the thermocouple at a depth of $65 \mathrm{~cm}$ (TCK065000000) reached $1200^{\circ} \mathrm{C}$, indicating that this region was beginning to fuse (or melt). At this time, the average electrode depth was $82.5 \mathrm{~cm}$. From these data, it appears that the molten 
pool became a continuous region between the electrode array at approximately run time hour 8 . As the test progressed, the centerline temperatures began to catch up to the depths of the electrodes. At the time of shutdown, the centerline thermocouple at $120 \mathrm{~cm}$ was at $1200^{\circ} \mathrm{C}$, with the average electrode depth at $120 \mathrm{~cm}$.

Figure 10 shows the centerline thermocouple temperatures above the starter path (the thermocouple tags are as described in the preceding paragraph). This array was suspended from above grade within the engineering-scale unit to ensure a constant position. It was also placed slightly off center to avoid any influence from and interference with the central vent pipe. From the temperature profile, it appears that the thermocouple at $45 \mathrm{~cm}$ (TCK045012270) remained just above the molten soil pool throughout the test. The sudden downward spikes seen in Figure 10 can be attributed to subsidence events, in which soil overburden sloughed onto the surface of the molten pool. As this relatively cooler soil moved downward, it affected the temperature profile being recorded by the thermocouple. Subsidence during the engineering-scale test was very pronounced and needs to be addressed for field-testing of the subsurface ISV process concept. This will ensure that, in actual applications, the off-gas hood is sufficiently sized to envelop the top surface of the melt zone.

These results demonstrate that the ISV process can be initiated from a subsurface starter path. They also confirm the utility of using a planar starter path (as opposed to a standard starter path, which consists of discrete, linear starter tube paths between electrodes). In addition, test results show that the process can be propagated downward and has a very good specific energy consumption ratio (0.77 kWh/kg vs. approximately $1 \mathrm{kWh} / \mathrm{kg}$ as previously reported). Based on the results from the engineering-scale tests, further study is warranted for evaluating subsurface initiation of the ISV process. However, observations during the engineering-scale test identify soil subsidence as an issue that needs to be addressed in advance of field-testing of the subsurface- 
started ISV process.

\section{ACKNOWLEDGMENTS}

The hot-tip portion of this work was performed in collaboration with the Geosafe Corporation. The Geosafe engineering-scale ISV system and site were used, together with Geosafe personnel, to perform the two tests described here. Support for PNL staff and equipment used in the hot-tip tests was provided by the U.S. Department of Energy EM-50 Branch as part of the Office of Technology Development's In Situ Remediation Integrated Program. The subsurface start-up work was supported by the U.S. Department of Energy EM-40 Branch. Both PNL projects were performed under contract DE-ACO6-76RLO 1830. The authors gratefully appreciate and acknowledge the support of these sponsors. 


\section{REFERENCES}

Brouns, R.A., J.L. Buelt, and W.F. Bonner. 1983. "In Situ Vitrification.” U.S. Patent 4,376,598. U.S. Patent Office, Washington, DC.

Buelt, J.L. C.L. Timmerman, K.H. Oma, V.F. Fitzpatrick, and J.G. Carter. 1987. In Situ Vitrification of Transuranic Waste: An Updated Systems Evaluation and Applications Assessment. PNL-4800, Suppl. 1. Pacific Northwest Laboratory, Richland, Washington.

Luey, J., T.D. Powell, W.O. Heath, and R.L. Richardson. 1992. Evaluation of New Concepts for In Situ Vitrification: Power System. Melt Insulation, and Off-Gas Containment. PNL-8231. Pacific Northwest Laboratory, Richland, Washington.

Tixier, J.S., J.A. Stottlemyre, and M.T. Murphy. -1991. "Vitrified Underground Barriers." In Waste Management‘91 vol 1, ed. R.G. Post, pp. 603-611.: February 24-28, 19.91, Tucson, Arizona.

Trent, D.S. and L.L. Eyler. TEMPEST: A computer Program for Three-Dimensional TimeDependent Computational Fluid Dynamics. PNL-8857, Vol. 2. Pacific Northwest Laboratory, Richland, Washington. 


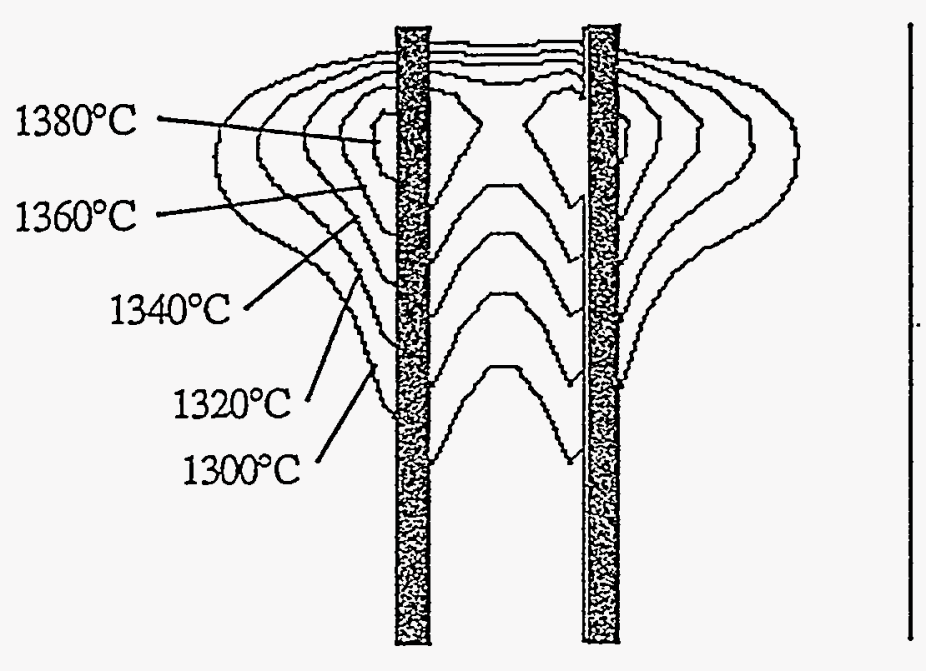

(a)

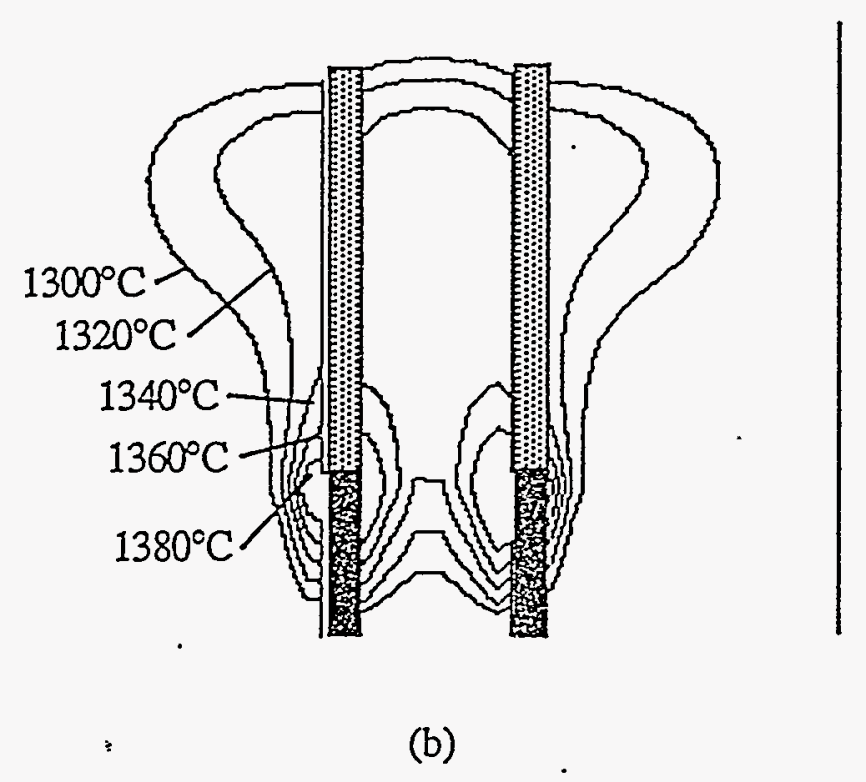

Figure 1. In-situ vitrification melt isotherms from TEMPEST simulations of engineering-scale systems employing: (a) standard and (b) 27-cm hot-tip electrodes. 


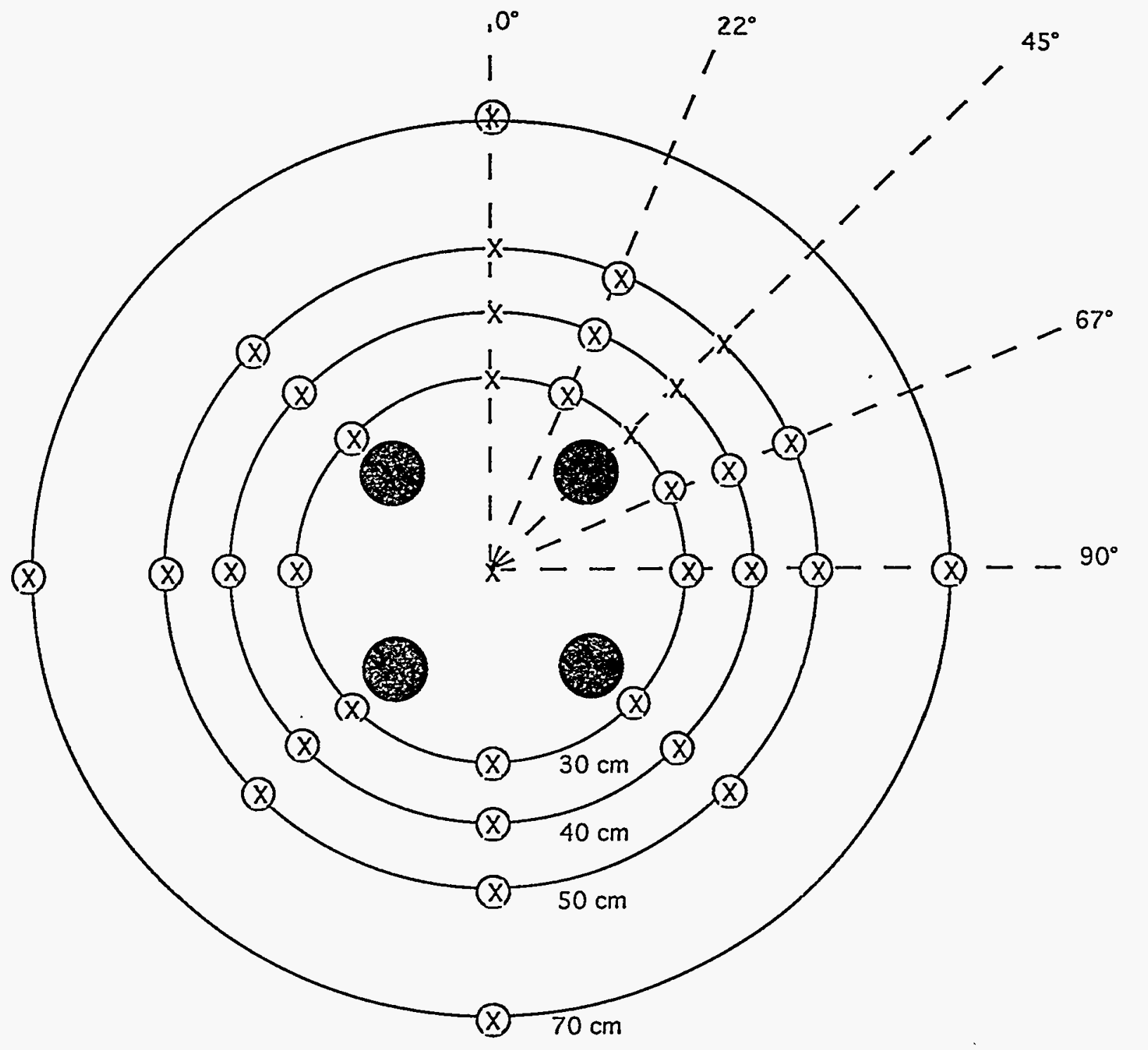

X) - Arrays of 5 type $K$ thermocouples spaced $20 \mathrm{~cm}$ apart (80-cm array length)

$X$ - Arrays of 10 type $K$ thermocouples spaced $10 \mathrm{~cm}$ apart (90-cm array length)

Figure 2. PNL/Geosafe engineering-scale in-situ vitrification test thermocouple layout schematic - plan view. 


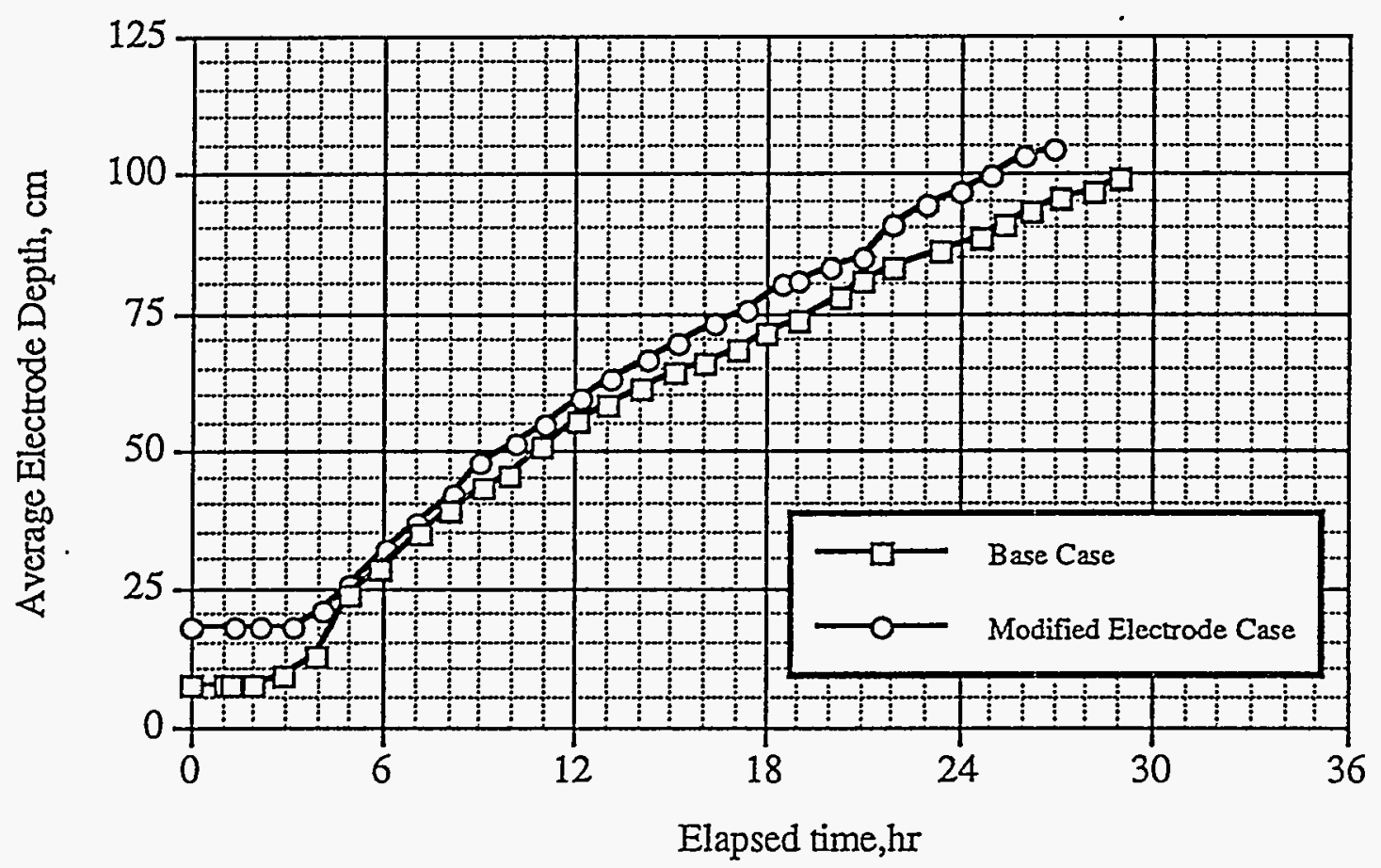

Figure 3. PNL/Geosafe engineering-scale in-situ vitrification electrode depth transients - standard vs. $30-\mathrm{cm}$ hot-tip electrode configuration results. 


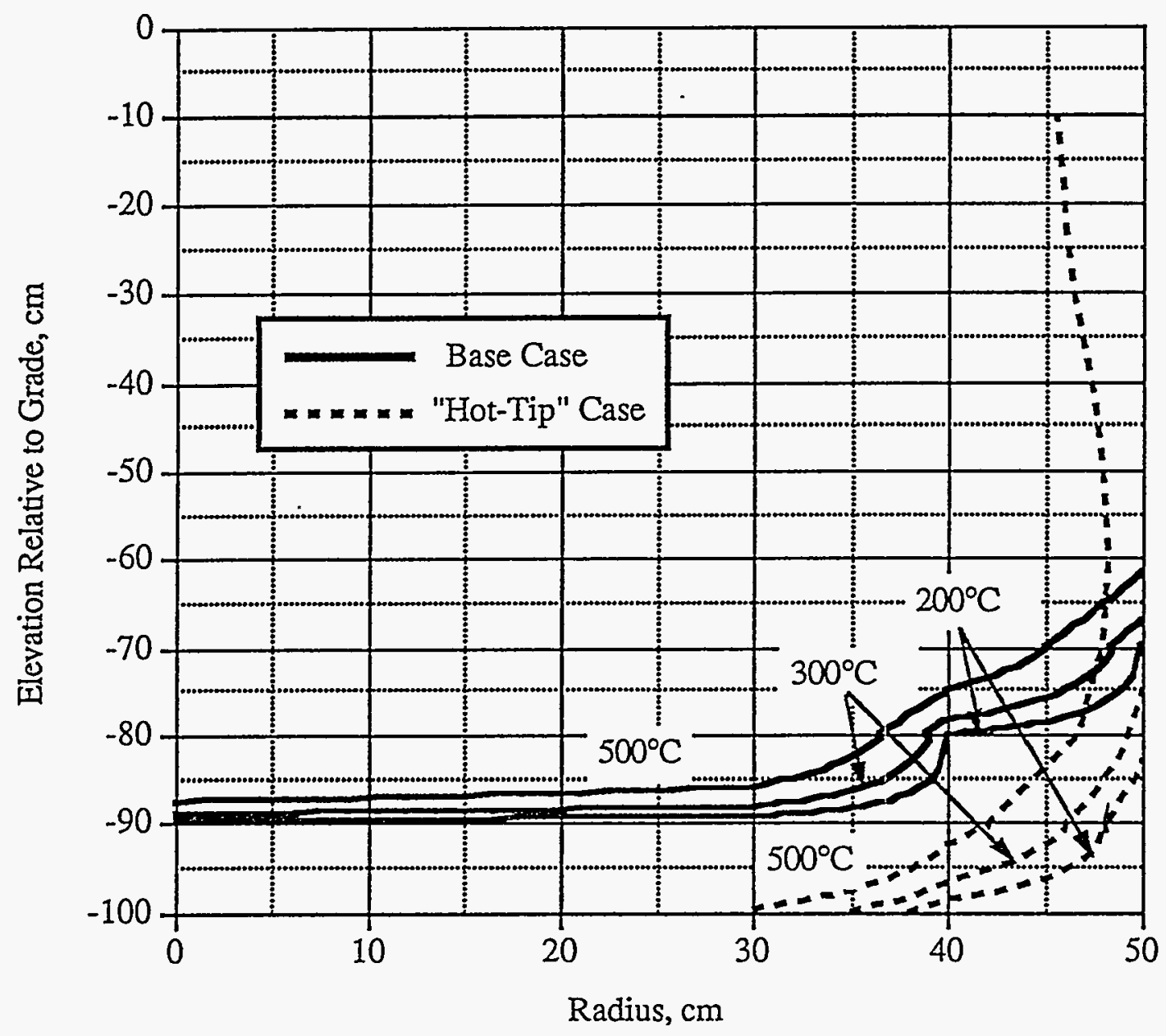

Figure 4. Base case vs. hot-tip isotherms along $0^{\circ}$ axis at $t=25 \mathrm{hr}$. 


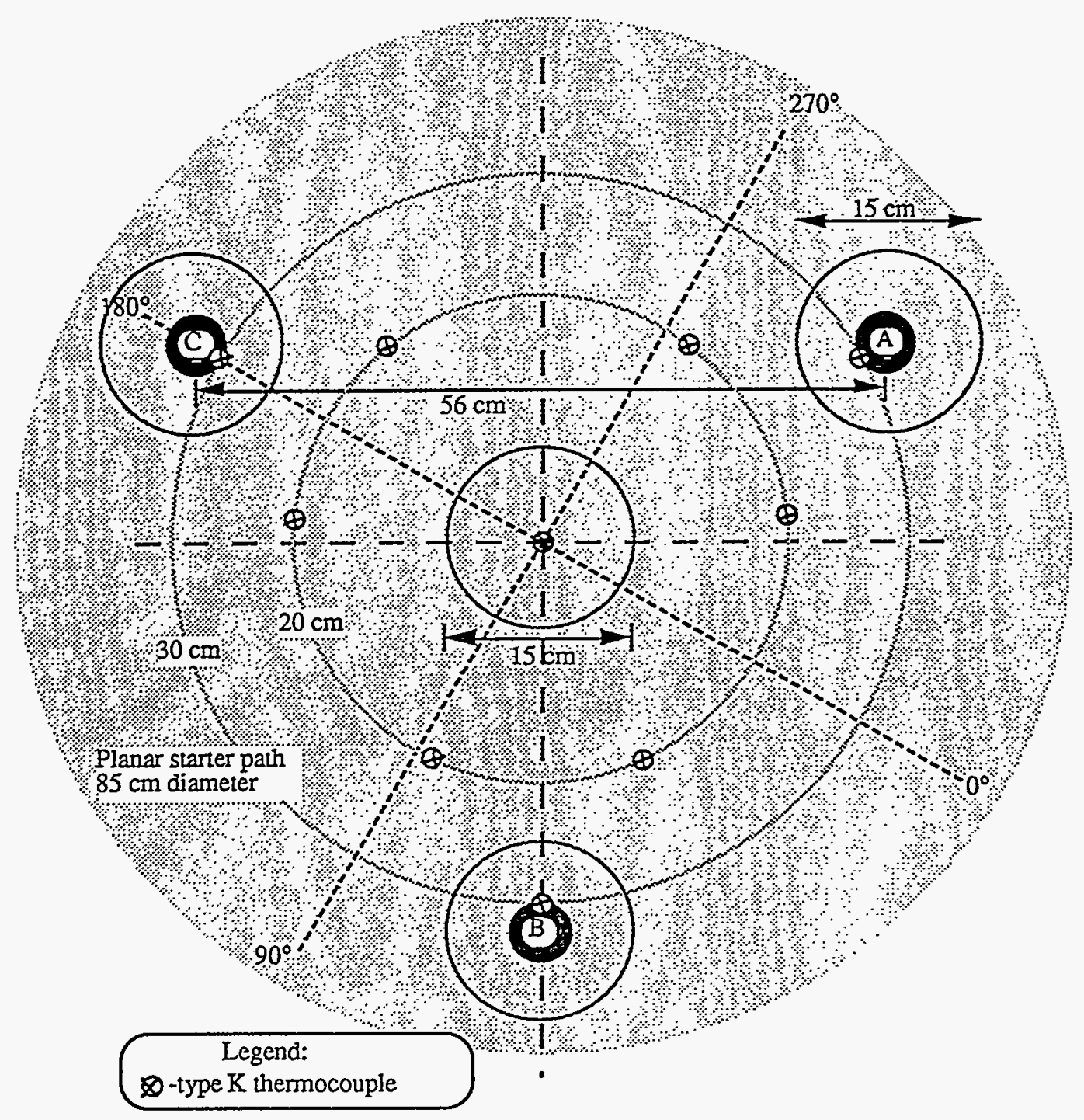

Figure 5. Initiation at depth, engineering-scale test layout - plan view. 


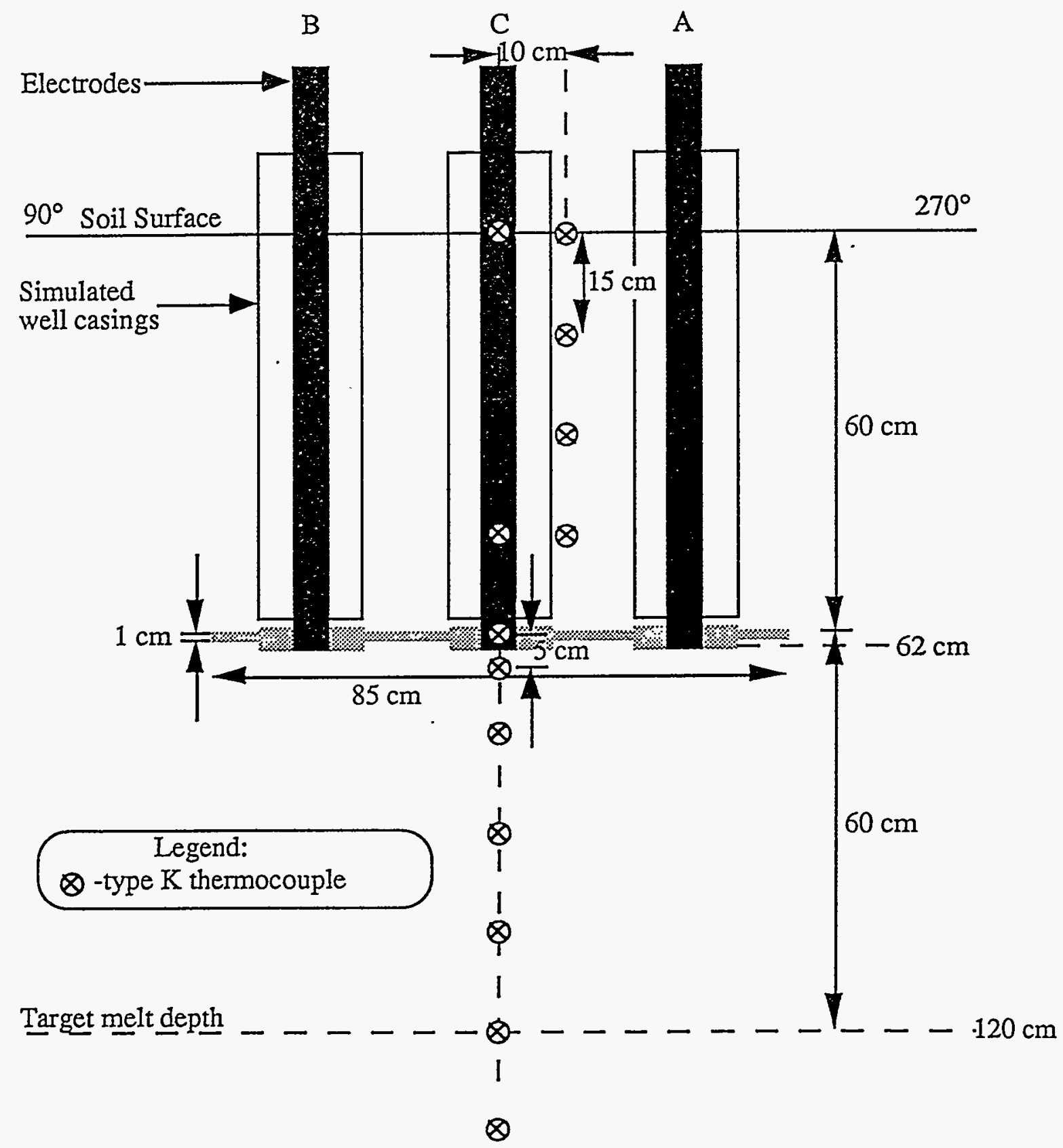

Figure 6. Initiation at depth, engineering-scale test layout - elevation view. 


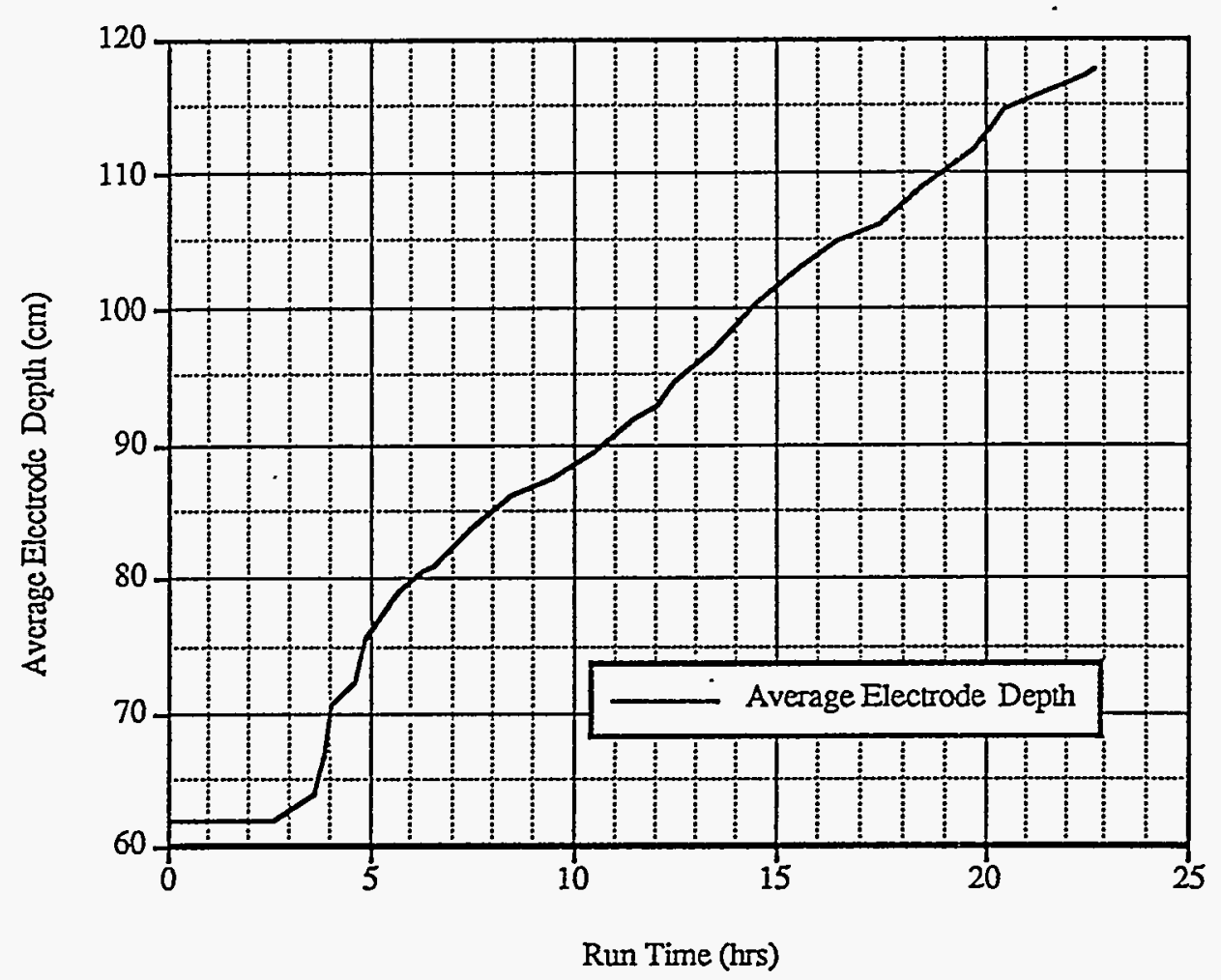

Figure 7. Power and energy consumption for initiation at depth, engineering-scale test. 


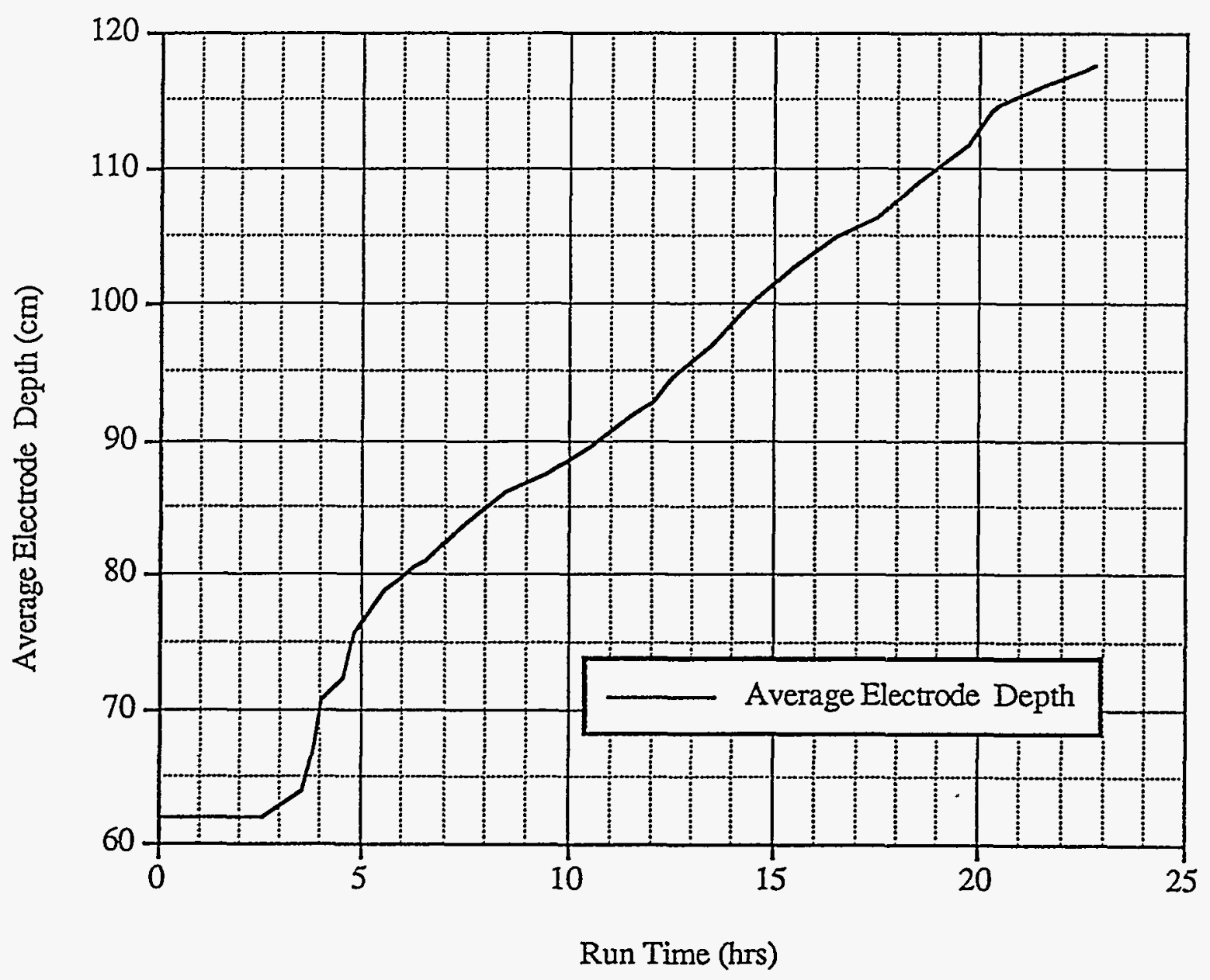

Figure 8. Average melt rate for initiation at depth, engineering-scale test. 


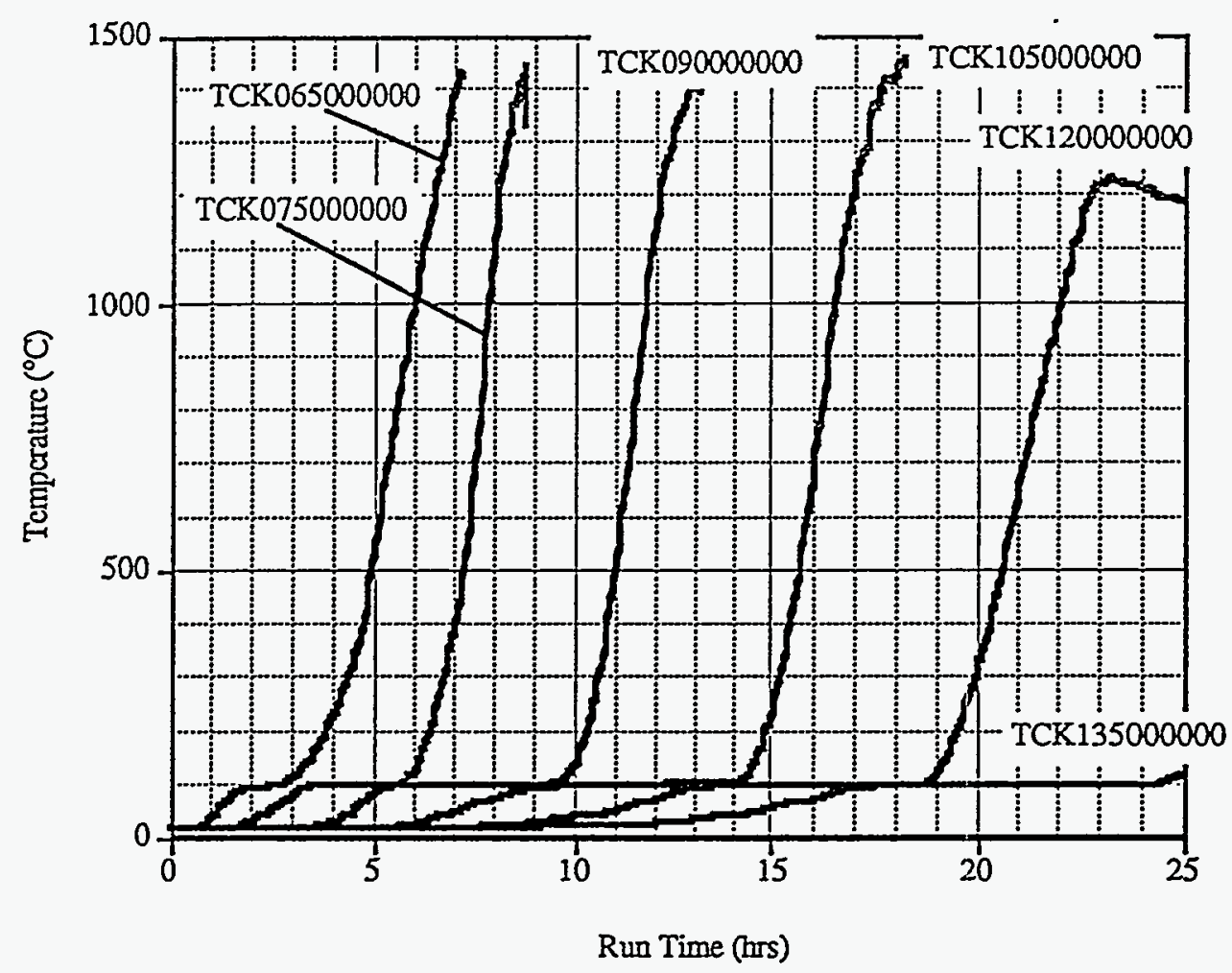

Figure 9. Temperature profile for centerline thermocouples below starter path. 


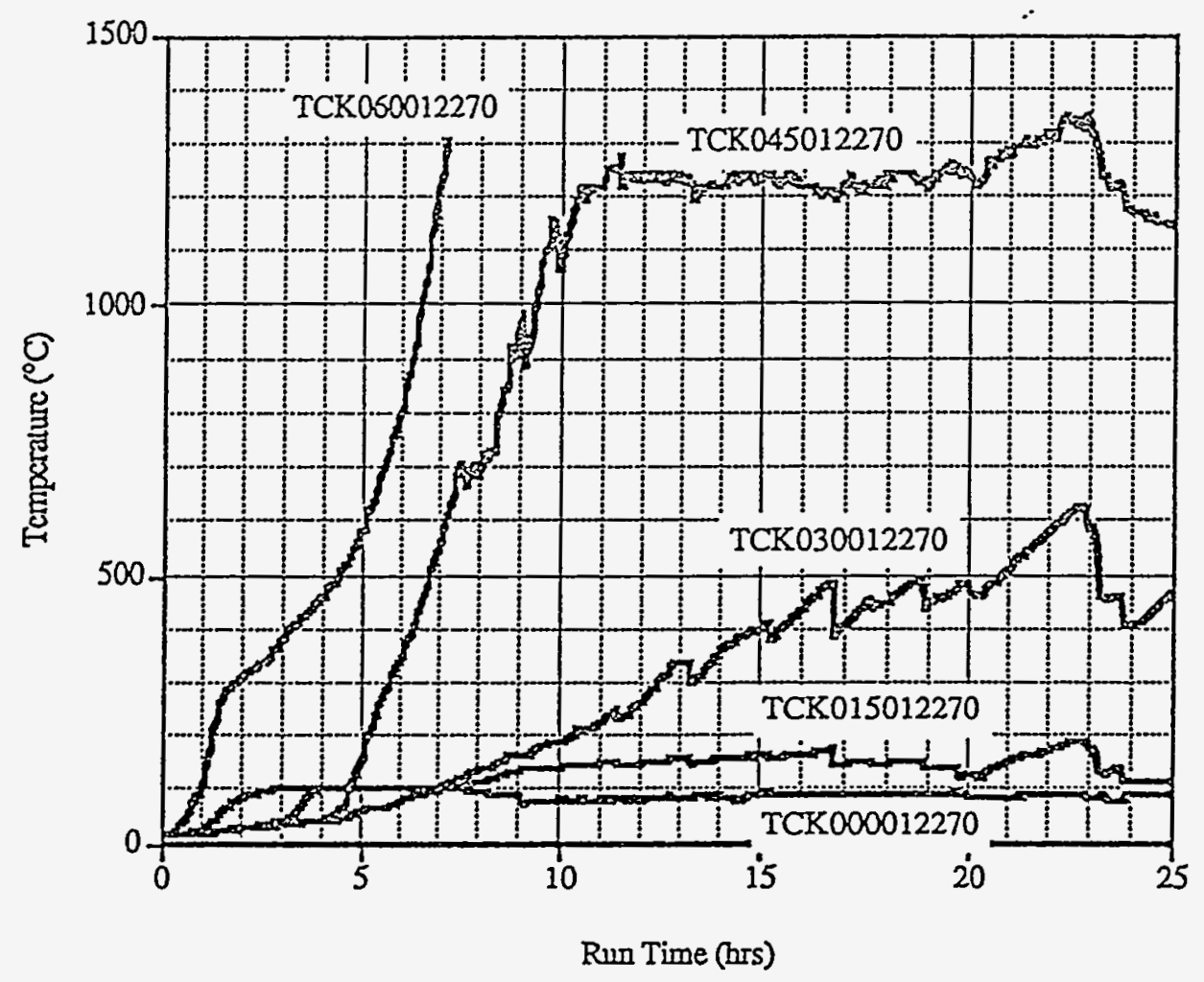

Figure 10. Temperature profile for centerline thermocouples above starter path. 
Cover:

Pacific Northwest Laboratory is operated by Battelle Memorial Institute for the U.S. Department of Energy under Contract DE-AC06-76RLO 1830.

This work is funded by the Office of Technology Development, within the Department of Energy's Office of Environmental

Management, under the [title of Integrated Demo or Program].

Inside Cover: 
[Disclaimer]

\section{Acknowledgements}

This work was prepared with the support of the following contributors:

Headquarters: $\quad$ Office of Technology Development

[title of Integrated Demo or Program]

[name of HQ Program Manager]

Operations Office: Richland Operations Office Technology Development Division

Deborah E. Trader, Technical Program Officer

Contractor: Pacific Northwest Laboratory

Environmental Management Directorate

Steven C. Slate, Technical Program Manager

[add subcontractors, etc. as appropriate] 


\section{DISCLAIMER}

This report was prepared as an account of work sponsored by an agency of the United States Government. Neither the United States Government nor any agency thereof, nor any of their employees, makes any warranty, express or implied, or assumes any legal liability or responsibility for the accuracy, completeness, or usefulness of any information, apparatus, product, or process disclosed, or represents that its use would not infringe privately owned rights. Reference herein to any specific commercial product, process, or service by trade name, trademark, manufacturer, or otherwise does not necessarily constitute or imply its endorsement, recommendation, or favoring by the United States Government or any agency thereof. The views and opinions of authors expressed herein do not necessarily state or reflect those of the United States Government or any agency thereof. 